friendly whilst still prompting the prescriber to meet prescribing gold standards and improve prescription safety.

\section{G129(P) AN UNUSUAL CASE OF NEONATAL METABOLIC ALKALOSIS CAUSING SEIZURES}

M Ranjan, H Gaili. Neonatology, Hull Royal Infirmary, Hull, UK

\subsection{6/archdischild-2018-rcpch. 125}

Introduction Metabolic alkalosis in neonates is very rare and attributed to gastric fluid losses, diuretics and congenital chloride diarrhoea $(\mathrm{CCH})$. There were four cases reported: due to maternal bulimia and Bartter's, vomiting and CCH. None of them had seizures.

Case report A new-born was born in good condition by emergency LSCS for IUGR, preeclampsia and suboptimal CTG. She developed desaturation of $80 \%$ at $30 \mathrm{~min}$ of age followed by apnoea and seizures. Antenatally, Mother had persistent vomiting for last one month, cocaine and amphetamine abuse and active Hepatitis $\mathrm{C}$ infection. The examination revealed irritability and hypertonia. Rest of the history and examination weren't significant. Mother and the baby showed hypochloraemic metabolic alkalosis with deranged renal function and electrolytes except potassium of 3.5 and 2.4 in baby and mother respectively; urine was positive for opiates and cocaine. CFAM showed seizure activities. EEG and MRI head were unremarkable. Infections and metabolic screening remained negative.

She was ventilated and treated with designer electrolytes solution, antibiotics and anticonvulsants. Due to renal impairment acyclovir was not given. Both made uneventful recovery.

Because of maternal substance abuse baby was discharged to grandparents with supervised access to parents.

Discussion

- Maternal hypochloremic metabolic alkalosis was likely secondary to prolonged vomiting

- The placental simple diffusion and haemodialysis effects explain the similar levels of electrolytes and renal function in mother and New-born except potassium.

- Initial normal $(3.5 \mathrm{mmol} / \mathrm{L})$ and later low $(2.4 \mathrm{mmol} / \mathrm{L})$ potassium levels are explainable by unidirectional placental potassium fluxes and intracellular shifting in alkalosis respectively.

- Desaturation and apnoea were due to shift of oxygen dissociation curve to left and hypoventilation by alkalosis.

- Early onset seizures were likely secondary to neuromuscular effect of alkalosis.

- This case illustrates the importance of close follow up of new-borns with maternal deranged electrolytes and renal impairment.

\section{REFERENCES}

1. Paediatric Metabolic Alkalosis. http://emedicine.medscape.com/article/906819overview

2. Voyame J, Terrier P, Guignard JP, Cachat F. Transient hypokalemic metabolic alkalosis in a newborn mimicking Bartter's syndrome. J Pediatr 1999;134:794.

3. McNanley T, Woods J. Glob. libr. women's med (ISSN: 1756-2228) 2008; doi:10.3843/GLOWM.10195

4. Stocker M. Metabolic alkalosis in a newborn infant. Swiss Society of Neonatology. www.neonet.chwebmaster@neonet.ch

\section{G130(P) AN UNUSUAL CAUSE OF DELAYED WALKING: A CASE PRESENTATION}

G Williams, K Mack. Department of Paediatrics, Scarborough Hospital, York Teaching Hospital Trust, Scarborough, UK

\subsection{6/archdischild-2018-rcpch.126}

We present a case of a 22-month-old girl who was found to have an underlying metabolic bone disease as a cause for delayed gross motor development.

The patient was referred to a district general hospital outpatient department as she was not yet cruising and had possible speech delay. However, she was crawling and had no fine motor or social developmental concerns. She had a normal birth history with no past medical or family history of note, her immunisations were up-to-date and she was on no medication. Examination showed her weight was on the 2nd-9th centile and her length was on the 0.4th centile. She had prominent notched clavicles with splayed wrists, mild scoliosis and a small thorax. She appeared to be in significant pain on hip abduction.

Bloods showed a significantly raised alkaline phosphatase (5882), but low corrected calcium and phosphate. Her 25 $(\mathrm{OH}) \mathrm{D}_{3}$ was normal but her parathyroid hormone was raised. Radiographs were consistent with features of rickets and she had femoral, radial and ulnar fractures. After $1,25(\mathrm{OH})_{2} \mathrm{D}_{3}$ was returned as slightly low at 47 , a diagnosis of 1-alphahydroxylase deficiency was made. She was commenced on oral alfacalcidol, calcium gluconate and phosphate. Upon review at 3 months, her biochemical markers were improved and she had made marked developmental progress.

1-alpha-hydroxylase deficiency was first identified in 1961 and is thought to be autosomal recessive with a mutation in the CYP27B1 gene, which prohibits conversion of $25(\mathrm{OH}) \mathrm{D}_{3}$ metabolite to the active $1,25(\mathrm{OH})_{2} \mathrm{D}_{3}$. Biochemical disturbance includes: moderate hypophosphataemia, severe hypocalcaemia, elevated parathyroid hormone and alkaline phosphatase, normal $25(\mathrm{OH}) \mathrm{D}_{3}$, and low $1,25(\mathrm{OH})_{2} \mathrm{D}_{3}$. Treatment aims to maintain corrected calcium levels within normal range by using large doses of $1,25(\mathrm{OH})_{2} \mathrm{D}_{3}$. The main concerns with treatment are nephrocalcinosis and intraocular calcification. Therefore, recommendations for monitoring are performing a bone profile, kidney function, parathyroid hormone and urinary calcium/creatinine ratio every 3 months and ophthalmology assessment, renal tract ultrasound and hand radiographs once per year.

\section{G131(P) ASSESSMENT OF INJURIES UNDER 1 YEAR OF AGE WITHIN A PAEDIATRIC EMERGENCY DEPARTMENT}

${ }^{1} \mathrm{C}$ McGowan, ${ }^{1} \mathrm{~J}$ Stirling, ${ }^{2} \mathrm{Z}$ Seow, ${ }^{1} \mathrm{M}$ Lilley. ${ }^{1}$ Paediatric Emergency Department, Royal Hospital Children, Glasgow, UK; ${ }^{2}$ School of Medicine, Dentistry and Nursing, Glasgow University, Glasgow, UK

\subsection{6/archdischild-2018-rcpch.127}

Aims To review our assessment of infants discharged directly from the emergency department who had presented with an injury under 1 year of age. To review adherence of usage of the injury under 1 proforma. To ascertain the number of children who had more than 1 injury under 1 year of age. To 